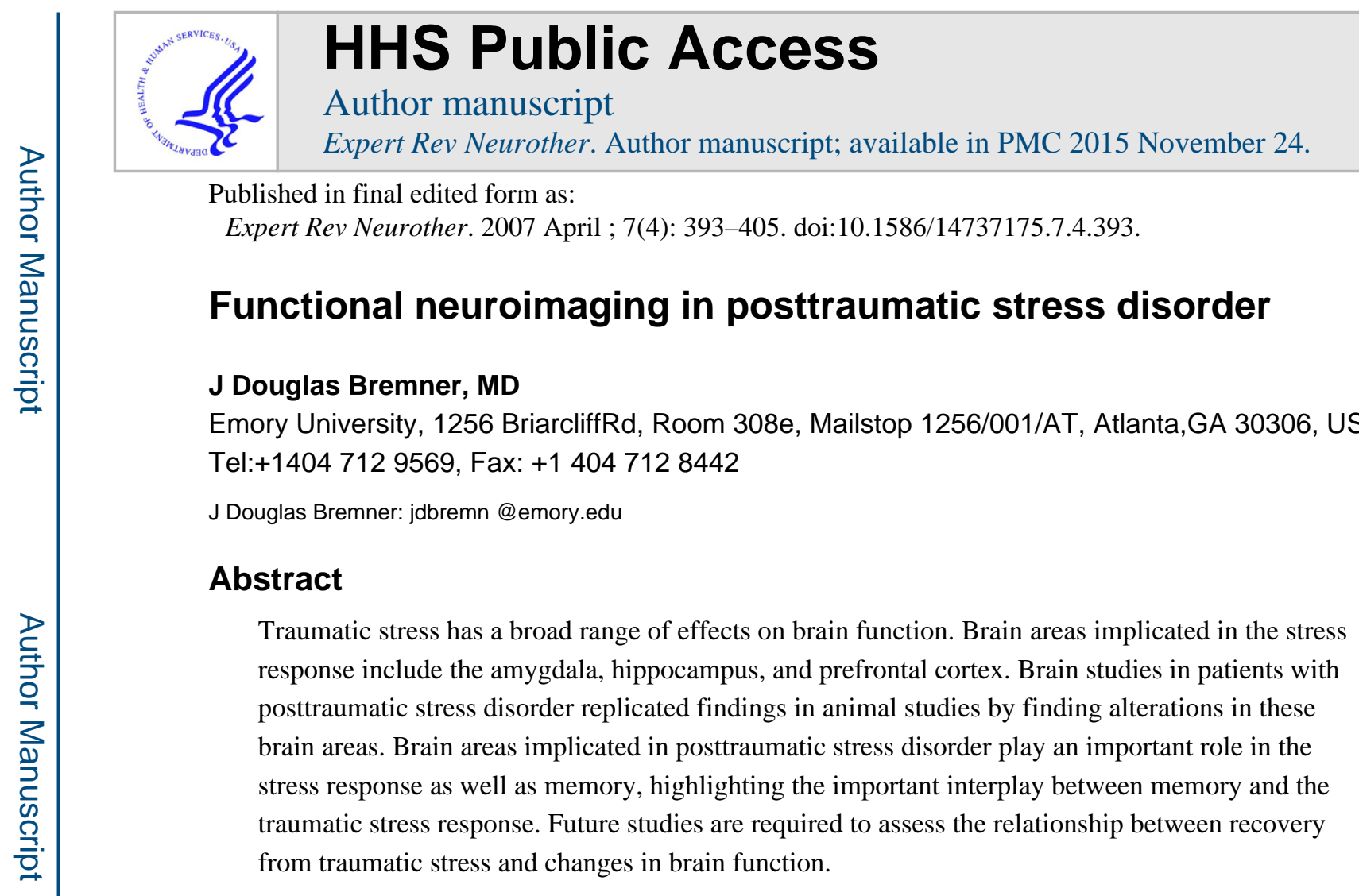

\title{
Keywords
}

depression; stress; PET; PTSD; neuroimaging

\section{Effects of traumatic stress}

Traumatic stressors such as early trauma can lead to posttraumatic stress disorder (PTSD), which affects approximately $8 \%$ of Americans at some time in their lives [1]. For many trauma victims, PTSD can be a lifelong problem [2]. The development of effective treatments for PTSD is limited by gaps in the knowledge about the underlying brain circuits that mediate symptoms of trauma-related disorders such as PTSD. Recent advances in neuroimaging over the past decade have opened a new window into understanding the changes in functional brain circuitry that underlie PTSD. This paper reviews functional brain imaging studies in the field of PTSD using positron-emission tomography (PET), single photon-emission computed tomography (SPECT) and magnetic resonance imaging (MRI). Studies of PTSD related to early abuse, combat, motor vehicle accident and other forms of traumatic stress will be discussed, with a focus on studies of brain function (as opposed to structure).

\section{Functional neuroimaging techniques}

The continuous progress of technology has been beneficial to our understanding of the underlying mechanisms in the brain that cause mental disorders. These techniques include MRI, PET and SPECT [3].

MRI has provided a major technological improvement in the imaging sciences. MRI uses a powerful magnet to throw the electrons that make up brain tissue out of their normal patterns 
and measures the time it takes for them to return to their normal 'resting' state. This relaxation time provides information about the content of the tissue, which can be used to create an image of the brain. More recently, MRI has been used to measure brain function, hence the term functional MRI (fMRI). This technique takes advantage of the fact that blood cells have small amounts of the metal heme, which has magnetic properties that can be measured by MRI. With activations of neurons in a specific part of the brain there is an increase in blood flow to that location; this changes the heme concentration in the blood, which is detected by fMRI. Brain function can also be measured with SPECT measurement of [ $\left.{ }^{99 \mathrm{~m}} \mathrm{TC}\right]$ hexamethylpropyleneamine oxime (HMPAO; a marker of brain blood flow) or PET measurement of O-radiolabeled water. PET can also be used to measure brain metabolism (or utilization of sugar) with radioactive glucose $\left(\left[{ }^{18} \mathrm{~F}\right] 2\right.$-fluoro-2-deoxyglucose [FDG]).

Functional neuroimaging studies can involve subtraction of an active task from a control task, hence a comparison of areas where there are greater differences in response between patients or controls can be made. This can be achieved with fMRI, PET or SPECT Alternatively, brain metabolism and blood flow can be measured and quantitated using PET. All of these paradigms represent measures of neuronal function and in this paper the term 'function' is used to refer to all of these examples.

\section{Neural circuits of PTSD}

PTSD is characterized by specific symptoms, including intrusive thoughts, hyperarousal, flashbacks, nightmares and sleep disturbances, changes in memory and concentration, and startle responses. Symptoms of PTSD are hypothesized to represent the behavioral manifestation of stress-induced changes in brain structure and function. Stress results in acute and chronic changes in neurochemical systems and specific brain regions, which result in long-term changes in brain circuits, involved in the stress response [4-7]. Brain regions that are thought to play an important role in PTSD include the hippocampus, amygdala and medial prefrontal cortex (mPFC).

Preclinical and clinical studies have shown alterations in memory function following traumatic stress [8], as well as changes in a circuit of brain areas, including the hippocampus, amygdala and mPFC, which mediate alterations in memory [9]. The hippocampus, an area of the brain involved in verbal declarative memory, is very sensitive to the effects of stress. Stress in animals has been associated with damage to neurons in the CA3 region of the hippocampus (which may be mediated by hypercortisolemia, decreased brain-derived neurotropic factor [BDNF] and/or elevated glutamate levels) and inhibition of neurogenesis [10-15].

Antidepressant treatments were shown to block the effects of stress and/or promote neurogenesis [13,16-19]. Animal studies have demonstrated several agents with potentially beneficial effects on stress-induced hippocampal damage. It has been found that phenytoin blocks the effects of stress on the hippocampus, probably through modulation of excitatory amino acid-induced neurotoxicity [20]. Other agents, including tianeptine, dihydroepiandosterone and fluoxetine, have similar effects $[16,17,19,21-26]$. These 
medications may share a common mechanism of action through upregulation of the cAMP response element-binding protein (CREB), that leads to regulation of expression of specific target genes involved in structural modeling of the hippocampus. Such treatment effects on BDNF and trkB mRNA, can have long-term effects on brain structure and function. There is new evidence that neurogenesis is necessary for the behavioral effects of antidepressants [27,28], although this continues to be a topic of debate [25,29].

In addition to the hippocampus, other brain structures have been implicated in a neural circuitry of stress, including the amygdala and prefrontal cortex (PFC). The amygdala is involved in memory for the emotional valence of events and plays a critical role in the acquisition of fear responses [30]. The mPFC includes the anterior cingulate gyrus (Brodmann's area [BA] 32) and subcallosal gyrus (area 25), as well as the orbitofrontal cortex. Lesion studies have demonstrated that the mPFC modulates emotional responsiveness through inhibition of amygdala function [31]. Studies show that neurons of the $\mathrm{mPFC}$ play an active role in inhibition of fear responses that are mediated by the amygdala [32,33]. Conditioned fear responses are extinguished following repeated exposure to the conditioned stimulus (in the absence of the unconditioned [aversive, e.g., electric shock stimulus). This inhibition appears to be mediated by $\mathrm{mPFC}$ inhibition of amygdala responsiveness. Animal studies have also shown that early stress is associated with a decrease in branching of neurons in the mPFC [34].

\section{Pharmacological treatment of PTSD}

Intervening soon after the trauma event is critical for long-term outcomes, since traumatic memories become indelible and resistant to treatment with time [35]. Pharmacological treatment of chronic PTSD has shown efficacy, originally for imipramine [36], amitriptyline [37] and phenalzine [36], and later for brofaramine [38], paroxetine [39,40] and sertraline [41]. These medications actually decrease the core symptoms of PTSD. For this reason, selective serotonin-reuptake inhibitors (SSRIs) are now recommended as first-line treatment for PTSD [42-47]. The utility of early treatment is also demonstrated by animal studies, showing that pretreatment before stress with antidepressants reduces chronic behavioral deficits related to stress $[48,49]$. As reviewed above, antidepressants including both norepinephrine as well as gabapentin and phenytoin, promote neurogenesis in the hippocampus, while stress inhibits neurogenesis [16,17,19,22,24,28,50]. This is important since hippocampal neurogenesis has been shown to be required for an antidepressant response [27].

\section{Functional neuroimaging studies in PTSD}

Imaging studies of brain function in PTSD are consistent with dysfunction of the mPFC, amygdala and hippocampus [6,51-57]. The methodology of imaging studies in PTSD is outlined in TABLE 1 and a summary of findings by author and brain region in TABLE 2 . Studies of resting blood flow or metabolism with PET and SPECT showed alterations at rest in medial, temporal and dorsolateral PFC, cerebellum, and amygdala [58-60]. Stimulation of the noradrenergic system with yohimbine resulted in activation failure in the dorsolateral prefrontal, temporal, parietal and orbitofrontal cortex, and decreased function in the 
hippocampus [60]. Exposure to traumatic reminders in the form of traumatic slides and/or sounds or traumatic scripts was associated with an increase in PTSD symptoms, decreased blood flow and/or activation failure of the mPFC/anterior cingulate, including BA 25 or subcallosal gyrus, area 32 and 24, as measured with PET, SPECT or fMRI (FIGURE 1) [6175]. Other findings in studies of traumatic-reminder exposure include decreased function in the hippocampus [65], thalamus [64,66], visual-association cortex $[64,65,69,70]$, parietal cortex [65,68,69,76,77] and inferior frontal gyrus [64,65,68,69,73,76,77], In addition to increased function in amygdala $[67,70,76]$, posterior cingulate $[63,65,66,69]$ and parahippocampal gyri $[63,65,67]$. Shin and colleagues found a correlation between increased amygdala function and decreased mPFC function with traumatic reminders [70], indicating that a failure of inhibition of the amygdala by the mPFC could account for increased PTSD symptoms with traumatic reminders. Other studies found increased amygdala and parahippocampal function and decreased mPFC function during performance of an attention task [71], increased amygdala function at rest [59], during a working-memory task [78], during recall of traumatic words [79], with exposure to masked, fearful faces [80,81], overtly fearful faces [72], traumatic sounds [67,82] and traumatic scripts [76].

Several studies have examined neural correlates of cognitive tasks in PTSD. During working-memory tasks, patients showed decreased inferior frontal [83] and parietal function [78,83]. Retrieval of emotionally valenced words [84] (e.g., 'rape/mutilate') in women with PTSD from early abuse resulted in decreases in blood flow in an extensive area, which included the orbitofrontal cortex, anterior cingulate and mPFC (BAs 25, 32 and 9), left hippocampus and fusiform gyrus/inferior temporal gyrus, with increased activation in the posterior cingulate, left inferior parietal cortex, left middle frontal gyrus and visual association and motor cortex [85]. Another study found a failure of meadial prefrontal cortical/anterior cingulate activation and decreased visual association and parietal cortex function in women who had suffered from abuse and PTSD compared with women who had suffered from abuse without PTSD, during performance of the emotional Stroop task (e.g., naming the color of a word such as 'rape') [86]. Shin and colleagues showed increased posterior cingulate and parahippocampal gyrus and decreased medial prefrontal and dorsolateral prefrontal cortical activity during an emotional 'counting' Stroop paradigm with fMRI [73].

Studies have also used declarative memory tasks as specific probes of hippocampal function. We measured brain activation with a paragraph encoding task in conjunction with PET ${ }^{15} \mathrm{O}$ water measurement of brain blood flow. Women with abuse and PTSD showed a failure of hippocampal activation during the memory task relative to controls [87]. In this study, women who had suffered abuse and were diagnosed with PTSD also had smaller hippocampal volume measured with MRI relative to both women with abuse without PTSD and nonabused non-PTSD women. The failure of hippocampal activation was significant after controlling differences in hippocampal volume as well as accuracy of encoding. Shin and colleagues also found a failure of hippocampal activation with a memory stem completion task in PTSD [88]. Astur and colleagues found deficits in hippocampal activation in PTSD with a computerized underwater maze task [103]. 
Although multiple studies have used symptom provocation with traumatic scripts or similar designs, little has been done in the area of fear conditioning in PTSD. To that end, we studied women with a history of severe childhood sexual abuse and the diagnosis of current PTSD $(n=8)$, and women without childhood abuse or PTSD $(n=11)$. All subjects underwent PET measurement of cerebral blood flow and psychophysiology measurement of heart rate and skin conductance (SC) during habituation, acquisition and extinction conditions on a single day, with scanning during a control condition on another day, separated by 1 week from the active condition. During habituation subjects were repeatedly exposed to a blue square on a screen (conditioned stimulus [CS]), during active-fearacquisition, exposure to the blue square (CS) was paired with an electric shock to the forearm (unconditioned stimulus [UCS]). During extinction subjects were again exposed to the blue squares (CS) without shock (active extinction). On a second day, subjects went through the same procedure with electric shocks delivered randomly when the blue square was not present (unpaired CS-UCS). Acquisition of fear was associated with increased SC responses to $\mathrm{CS}$ exposure during the active versus the control conditions in all subjects. There was increased SC for PTSD during the first CS-UCS presentation. Extinction of fear was associated with increased SC responses to CS exposure during the active versus the control conditions in all subjects. When PTSD and non-PTSD subjects were examined separately, SC levels were significantly elevated in non-PTSD subjects undergoing extinction following the active compared with the control condition during session one. PTSD subjects showed activation of the bilateral amygdala during fear acquisition compared with the control condition (FIGURE 2). Non-PTSD subjects showed an area of activation in the region of the left amygdala. When PTSD subjects and control subjects were directly compared, PTSD subjects showed greater activation of the left amygdala during the fear conditioning condition (pairing of US and CS) relative to the random shock control than healthy women. Other areas that showed increased activation with fear acquisition in PTSD included bilateral superior temporal gyrus (BA 22), cerebellum, bilateral inferior frontal gyrus (BA 44, 45) and posterior cingulate (BA 24). Fear acquisition was associated with decreased function in $\mathrm{mPFC}$, visual association cortex and medial temporal cortex, inferior parietal lobule and other areas. Extinction of fear responses was associated with decreased function in the orbitofrontal and mPFC (including subcallosal gyrus, BA 25 and anterior cingulate, BA 32), visual association cortex and other areas in the PTSD subjects, but not in the controls. Amygdala blood flow with fear acquisition was negatively correlated with medial prefrontal blood flow with fear extinction (increased blood flow in amygdala correlated with decreased blood flow in $\mathrm{mPFC}$ ) in all subjects (correlation coefficient $[\mathrm{r}]=$ $-0.48 ; \mathrm{p} 0.05)$. Increased amygdala blood flow with fear acquisition was positively correlated with PTSD $(r=0.45)$, anxiety $(r=0.44)$ and dissociative $(r=0.80)$ symptom levels in PTSD (but not non-PTSD) subjects. There was a negative correlation between medial prefrontal blood flow during extinction and anxiety as measured with the Panic Attack Symptom Scale during extinction in the PTSD group, which was only significant after correction for multiple comparisons $(r=-0.90 ; p=0.006)$ [89]. This study was consistent with increased amygdala function with fear acquisition and decreased medial prefrontal (anterior cingulate) function during extinction in PTSD. This is consistent with the model of an overactive amygdala and a failure of mPFC to extinguish, or shut off, the amygdala when the acute threat is no longer present. 
We have tested the hypothesis that patients with trauma-related psychiatric disorders, which have been described as 'trauma spectrum' disorders [5], have common abnormalities in specific brain areas, including the amygdala, $\mathrm{mPFC}$ and hippocampus. These disorders include abuse-rated PTSD, depression associated with early abuse, borderline personality disorder (BPD) associated with early abuse and dissociative identity disorder (DID) with early abuse. To test this hypothesis we exposed traumatized women with and without BPD to the stress of a script outlining a personally upsetting abandonment scene in conjunction with PET imaging of the brain [90]. Women with BPD exhibited a relative failure of medial prefrontal activation during abandonment scripts compared with non-BPD females. Women with BPD and abuse had increased psychophysiological responses to abandonment scripts relative to trauma scripts, while women with PTSD and abuse had the opposite pattern [91], indicating differential responding in these two disorders in spite of the common exposure to early abuse. Studies of structural MRI have also shown smaller hippocampal volume across several trauma spectrum disorders, including abuse-related PTSD [87,92], DID with early abuse [93], BPD with early abuse [94] and depression with early abuse [95].

In summary, these studies are consistent with dysfunction of a circuit involving the mPFC, dorsolateral PFC and hippocampus and amygdala, in PTSD patients that we hypothesize underlie symptoms of PTSD.

\section{Effects of pharmacotherapy on brain function \& structure in PTSD}

We have begun to assess the effects of pharmacotherapy on brain structure and function in PTSD [96]. We recently assessed the effects of phenytoin on brain structure and function. Studies in animals show that phenytoin, which is used in the treatment of epilepsy and is known to modulate glutamatergic function, blocks the effects of stress on the hippocampus [20]. We studied nine patients with PTSD in an open-label trial before and after treatment with phenytoin. Phenytoin resulted in a significant improvement in PTSD symptoms [97]. It also resulted in increases in both right hippocampal volume and hemisphere volume [98]. These findings indicate that phenytoin has an effect on PTSD symptoms as well as brain structure in PTSD patients. In a second study, patients with PTSD were shown to have an increase in hippocampal volume and memory function with paroxetine [99] and a decrease in Cortisol responsiveness to a stressful cognitive challenge [100]. One case report showed decreased inferior frontal, prefrontal and insula blood flow measured with PET in response to war-related sounds. These changes normalized with successful treatment with the SSRI fluoxetine [101]. Another study assessed resting brain blood flow with SPECT ${ }^{99 \mathrm{~m}} \mathrm{TC}$ HMPAO before and after 8 weeks of open-label treatment with the SSRI Citalopram, in 11 adult patients with PTSD. Treatment resulted in a decrease in left medial temporal cortex blood flow. Decreased PTSD symptoms as measured with the Clinician Administered PTSD Scale were correlated with increased function in the mPFC [102].

\section{Summary \& conclusions}

Traumatic stress has a broad range of effects on brain function. Brain areas implicated in the stress response include the amygdala, hippocampus and PFC. These brain areas also play a critical role in memory, highlighting the important interplay between memory and the 
traumatic-stress response. Preclinical studies show that stress affects these brain areas. Furthermore, antidepressants have effects on the hippocampus that counteract the effects of stress. In fact, promotion of neurogenesis in the hippocampus may be central to the efficacy of antidepressants. Studies in patients with PTSD show alterations in brain areas implicated in animal studies, including the amygdala, hippocampus and PFC. Increased amygdala activation with acquisition of fear responses and a failure of the $\mathrm{mPFC}$ to properly mediate extinction, are hypothesized to underlie symptoms of PTSD. Treatments that are efficacious for PTSD show a promotion of neurogenesis in animal studies, as well as promotion of memory and increased hippocampal volume in PTSD. Future studies are needed to assess neural mechanisms in treatment responses in PTSD. In addition, studies need to move beyond assessments of brain function and examine areas sucn as neuroreceptor binding and changes in brain chemicals (e.g., with magnetic resonance spectroscopy).

\section{Expert commentary}

Functional neuroimaging studies have identified abnormalities in brain function in PTSD, including increased amygdala function and decreased medial prefrontal and hippocampal function.

These brain abnormalities likely underlie a failure to extinguish traumatic memories.

Almost no studies have examined the effects of antidepressants on brain function or the relationship between recovery from traumatic stress and changes in brain function.

Future studies will assess the effects of treatments on brain function and the relationship between natural recovery from trauma and changes in brain function.

\section{Five-year view}

The past decade has seen remarkable progress in the field of functional brain imaging. We have gone from literally no published studies in the field 10 years ago, to the current situation where there is an ever-expanding number of publications. Most of the studies to date have appropriately examined the effects of stimulating PTSD symptoms on brain function. These studies have used scripts of traumatic events or trauma-related slides and sounds to provoke symptoms that are specific to that particular person's trauma. This was an appropriate place for the field to start, being the most salient to understanding the core clinical presentation of PTSD. After that wave of initial studies, investigators started to look at neural correlates of abnormal cognition in PTSD, such as neural correlates of deficits in verbal declarative memory, or other paradigms, such as inhibition of responsiveness with emotional Stroop paradigms. Studies have just begun to examine neural correlates of classic fear conditioning, or the effects of treatment on brain function. I predict that 5 years from now there will be many more studies of this type. In addition, changes in brain chemicals and neuroreceptor binding will be better understood; a topic which has received essentially no attention up to this point. 


\section{References}

1. Kessler RC, Sonnega A, Bromet E, Hughes M, Nelson CB. Posttraumatic stress disorder in the national comorbidity survey. Arch Gen Psychiatry. 1995; 52:1048-1060. [PubMed: 7492257]

2. Saigh, PA.; Bremner, JD. Posttraumatic Stress Disorder: A Comprehensive Text. Allyn \& Bacon; Needham Heights, MA, USA: 1999.

3. Bremner, JD. Brain Imaging Handbook. WW Norton; NY, USA: 2005.

4. Vermetten E, Bremner JD. Circuits and systems in stress. II. Applications to neurobiology and treatment of PTSD. Depress Anxiety. 2002; 16:14-38. [PubMed: 12203669]

5. Bremner, JD. Does Stress Damage the Brain? Understanding Trauma-related Disorders from a Mind-Body Perspective. WW Norton; NY, USA: 2002.

6. Pitman RK. Investigating the pathogenesis of posttraumatic stress disorder with neuroimaging. $\mathrm{J}$ Clin Psychiatry. 2001; 62:47-54. [PubMed: 11495097]

7. Vermetten E, Bremner JD. Circuits and systems in stress. I. Preclinical studies. Depress Anxiety. 2002; 15:126-147. [PubMed: 12001181]

8. Elzinga BM, Bremner JD. Are the neural substrates of memory the final common pathway in PTSD? J Affect Disord. 2002; 70:1-17. [PubMed: 12113915]

9. Bremner JD. Functional neuroanatomical correlates of traumatic stress revisited 7 years later, this time with data. Psychopharmacol Bull. 2003; 37(2):6-25. [PubMed: 14566211]

10. Gould E, Tanapat P, McEwen BS, Flugge G, Fuchs E. Proliferation of granule cell precursors in the dentate gyrus of adult monkeys is diminished by stress. Proc Natl Acad Sei USA. 1998; 95:3168-3171.

11. Magarinos AM, McEwen BS, Flugge G, Fluchs E. Chronic psychosocial stress causes apical dendritic atrophy of hippocampal CA3 pyramidal neurons in subordinate tree shrews. J Neurosci. 1996; 16:3534-3540. [PubMed: 8627386]

12. McEwen BS, Angulo J, Cameron H, et al. Paradoxical effects of adrenal steroids on the brain: protection versus degeneration. Biol Psychiatry. 1992; 31:177-199. [PubMed: 1737079]

13. Nibuya M, Morinobu S, Duman RS. Regulation of BDNF and trkB mRNA in rat brain by chronic electroconvulsive seizure and antidepressant drug treatments. J Neurosci. 1995; 15:7539-7547. [PubMed: 7472505]

14. Sapolsky RM, Uno H, Rebert CS, Finch CE. Hippocampal damage associated with prolonged glucocorticoid exposure in primates. J Neurosci. 1990; 10:2897-2902. [PubMed: 2398367]

15. Sapolsky RM. Why stress is bad for your brain. Science. 1996; 273:749-750. [PubMed: 8701325]

16. Malberg JE, Eisch AJ, Nestler EJ, Duman RS. Chronic antidepressant treatment increases neurogenesis in adult rat hippocampus. J Neurosci. 2000; 20:9104-9110. [PubMed: 11124987]

17. Czeh B, Michaelis T, Watanabe T, et al. Stress-induced changes in cerebral metabolites, hippocampal volume, and cell proliferation are prevented by antidepressant treatment with tianeptine. Proc Natl Acad Sei USA. 2001; 98:12796-12801.

18. Santarelli L, Saxe M, Gross C, et al. Requirement of hippocampal neurogenesis for the behavioral effects of antidepressants. Science. 2003; 301(5634):805-809. [PubMed: 12907793]

19. Lucassen PJ, Fuchs E, Czeh B. Antidepressant treatment with tianeptine reduces apoptosis in the hippocampal dentate gyrus and temporal cortex. Eur J Neurosci. 2004; 14:161-166. [PubMed: 11488960]

20. Watanabe YE, Gould H, Cameron D, Daniels D, McEwen BS. Phenytoin prevents stress and corticosterone induced atrophy of CA3 pyramidal neurons. Hippocampus. 1992; 2:431-436. [PubMed: 1308199]

21. Garcia R. Stress, metaplasticity, and antidepressants. Curr Mol Med. 2002; 2:629-638. [PubMed: 12420802]

22. D’Sa C, Duman RS. Antidepressants and neuroplasticity. Bipolar Disorder. 2002; 4:183-194.

23. Duman RS, Heninger GR, Nestler EJ. A molecular and cellular theory of depression. Arch Gen Psychiatry. 1997; 54:597-606. [PubMed: 9236543]

24. Duman RS, Malberg JE, Nakagawa S. Regulation of adult neurogenesis by psychotropic drugs and stress. J Pharmacol Exp Ther. 2001; 299:401-407. [PubMed: 11602648] 
25. Duman RS. Depression: a case of neuronal life and death? Biol Psychiatry. 2004; 56:140-145. [PubMed: 15271581]

26. McEwen BS, Chattarji S. Molecular mechanisms of neuroplasticity and pharmacological implications: the example of tianeptine. Eur Neuropsychopharmacol. 2004; 14(Suppl. 5):S497S502. [PubMed: 15550348]

27. Santarelli L, Saxe M, Gross C, et al. Requirement of hippocampal neurogenesis for the behavioral effects of antidepressants. Science. 2003; 301:805-809. [PubMed: 12907793]

28. Watanabe Y, Gould E, Daniels DC, Cameron H, McEwen BS. Tianeptine attenuates stress-induced morphological changes in the hippocampus. Eur J Pharmacol. 1992; 222:157-162. [PubMed: 1468492]

29. Henn FA, Vollmayr B. Neurogenesis and depression: etiology or epiphenomenon? Biol Psychiatry. 2004; 56:146-150. [PubMed: 15271582]

30. Davis M. The role of the amygdala in fear and anxiety. Annu Rev Neurosci. 1992; 15:353-375. [PubMed: 1575447]

31. Morgan CA, Romanski LM, LeDoux JE. Extinction of emotional learning: contribution of medial prefrontal cortex. Neurosci Lett. 1993; 163:109-113. [PubMed: 8295722]

32. Milad MR, Quirk GJ. Neurons in medial prefrontal cortex signal memory for fear extinction. Nature. 2002; 420:70-73. [PubMed: 12422216]

33. Milad MR, Rauch SL, Pitman RK, Quirk GJ. Fear extinction in rats: implications for human brain imaging and anxiety disorders. Biol Psychol. 2006; 73(1):61-71. [PubMed: 16476517]

34. Radley JJ, Sisti HM, Hao J, et al. Chronic behavioral stress induces apical dendritic reorganization in pyramidal neurons of the medial prefrontal cortex. Neuroscience. 2004; 125(1):1-6. [PubMed: 15051139]

35. Meadows, EA.; Foa, EB. Cognitive-behavioral treatment of traumatized adults. In: Saigh, PA.; Bremner, JD., editors. Posttraumatic Stress Disorder: A Comprehensive Text. Allyn \& Bacon; Needham Heights, MA, USA: 1999. p. 376-390.

36. Frank JB, Kosten TR, Giller EL, Dan E. A randomized clinical trial of phenelzine and imipramine for posttraumatic stress disorder. Am J Psychiatry. 1988; 145:1289-1291. [PubMed: 3048121]

37. Davidson J, Kudler H, Smith R, et al. Treatment of posttraumatic stress disorder with amitriptyline and placebo. Arch Gen Psychiatry. 1990; 47(3):259-266. [PubMed: 2407208]

38. Baker DG, Diamond BI, Gillette G, et al. A double-blind, randomized, placebo-controlled, multicenter study of brofaromine in the treatment of posttraumatic stress disorder. Psychopharmacology. 1995; 122:386-389. [PubMed: 8657838]

39. Tucker P, Zaninelli R, Yehuda R, et al. Paroxetine in the treatment of chronic posttraumatic stress disorder: results of a placebo-controlled flexible-dosage trial. J Clin Psychiatry. 2001; 62(11):860868. [PubMed: 11775045]

40. Marshall RD, Beebe KL, Oldham M, Zaninelli R. Efficacy and safety of paroxetine treatment for chronic PTSD: a fixed-dose, placebo-controlled study. Am J Psychiatry. 2001; 158(11):19821988. [PubMed: 11729013]

41. Brady KT, Pearlstein T, Asnis GM, et al. Efficacy and safety of sertraline treatment of posttraumatic stress disorder: a randomized controlled trial. JAMA. 2000; 283:1837-1844. [PubMed: 10770145]

42. Foa EB, Davidson JRT, Frances A, et al. The expert consensus guideline series: treatment of posttraumatic stress disorder. J Clin Psychiatry. 1999; 60:4-76.

43. Ballenger JC, Davidson JR, Lecrubier Y, et al. Consensus statement on posttraumatic stress disorder from the International Consensus Group on Depression and Anxiety. J Clin Psychiatry. 2000; 61:60-66. [PubMed: 10761680]

44. Davidson JR. Pharmacotherapy of posttraumatic stress disorder: treatment options, long-term follow-up, and predictors of outcome. J Clin Psychiatry. 2000; 61:52-56. [PubMed: 10761679]

45. Stein DJ, Seedat S, van der Linden GJ, Zungu-Dirwayi N. Selective serotonin reuptake inhibitors in the treatment of posttraumatic stress disorder: a meta-analysis of randomized controlled trials. Int Clin Psychopharmacol. 2000; 15:S31-S39. [PubMed: 11110017]

46. Davidson JR. Long-term treatment and prevention of posttraumatic stress disorder. J Clin Psychiatry. 2004; 65(Suppl. 1):44-48. [PubMed: 14728096] 
47. Davis LL, English BA, Ambrose SM, Petty F. Pharmacotherapy for posttraumatic stress disorder: a comprehensive review. Expert Opin Pharmacother. 2001; 2(10):1583-1595. [PubMed: 11825301]

48. Sherman AD, Petty F. Additivity of neurochemical changes in learned helplessness and imipramine. Behav Neurol Biol. 1982; 35:344-353.

49. Petty F, Kramer G, Wilson L. Prevention of learned helplessness: in vivo correlation with cortical serotonin. Pharmacol Biochem Behav. 1992; 43:361-367. [PubMed: 1438477]

50. Lee H, Kim JW, Yim SV, et al. Fluoxetine enhances cell proliferation and prevents apoptosis in dentate gyrus of maternally separated rats. Mol Psychiatry. 2001; 6:715-718.

51. Liberzon I, Phan KL. Brain-imaging studies of posttraumatic stress disorder. CNS Spectr. 2003; 8(9):641-650. [PubMed: 15079138]

52. Liberzon I, Martis B. Neuroimaging studies of emotional responses in PTSD. Ann NY Acad Sei. 2006; 1071:87-109.

53. Liberzon I, Britton JC, Phan KL. Neural correlates of traumatic recall in posttraumatic stress disorder. Stress. 2003; 6(3):151-156. [PubMed: 13129808]

54. Bremner JD. Neuroimaging of posttraumatic stress disorder. Psych Annal. 1998; 28:445-450.

55. Bremner JD. Neuroimaging of childhood trauma. Semin Clin Neuropsych. 2002; 7:104-112.

56. Rauch SL, Shin LM, Phelps EA. Neurocircuitry models of posttraumatic stress disorder and extinction: human neuroimaging research - past, present, and future. Biol Psychiatry. 2006; 60(4): 376-382. [PubMed: 16919525]

57. Cannistraro PA, Rauch SL. Neural circuitry of anxiety: evidence from structural and functional neuroimaging studies. Psychopharmacol Bull. 2003; 37(4):8-25. [PubMed: 15131515]

58. Bonne O, Gilboa A, Louzoun Y, et al. Resting regional cerebral perfusion in recent posttraumatic stress disorder. Biol Psychiatry. 2003; 54(10):1077-1086. [PubMed: 14625150]

59. Chung YA, Kim SH, Chung SK, et al. Alterations in cerebral perfusion in posttraumatic stress disorder patients without re-exposure to accident-related stimuli. Clin Neurophysiol. 2006; 117(3): 637-642. [PubMed: 16426890]

60. Bremner JD, Innis RB, Ng CK, et al. PET measurement of cerebral metabolic correlates of yohimbine administration in posttraumatic stress disorder. Arch Gen Psychiatry. 1997; 54:246256. [PubMed: 9075465]

61. Britton JC, Phan KL, Taylor SF, Fig LM, Liberzon I. Corticolimbic blood flow in posttraumatic stress disorder during script-driven imagery. Biol Psychiatry. 2005; 57(8):832-840. [PubMed: 15820703]

62. Yang P, Wu MT, Hsu CC, Ker JH. Evidence of early neurobiological alternations in adolescents with posttraumatic stress disorder: a functional MRI study. Neurosci Lett. 2004; 370(1):13-18. [PubMed: 15489009]

63. Bremner JD, Staib L, Kaloupek D, et al. Neural correlates of exposure to traumatic pictures and sound in Vietnam combat veterans with and without posttraumatic stress disorder: a positron emission tomography study. Biol Psychiatry. 1999; 45:806-816. [PubMed: 10202567]

64. Lanius RA, Williamson PC, Hopper J, et al. Recall of emotional states in posttraumatic stress disorder: an fMRI investigation. Biol Psychiatry. 2003; 53(3):204-210. [PubMed: 12559652]

65. Bremner JD, Narayan M, Staib LH, et al. Neural correlates of memories of childhood sexual abuse in women with and without posttraumatic stress disorder. Am J Psychiatry. 1999; 156:1787-1795. [PubMed: 10553744]

66. Lanius RA, Williamson PC, Densmore M, et al. Neural correlates of traumatic memories in posttraumatic stress disorder: a functional MRI investigation. Am J Psychiatry. 2001; 158:1920 1922. [PubMed: 11691703]

67. Liberzon I, Taylor SF, Amdur R, et al. Brain activation in PTSD in response to trauma-related stimuli. Biol Psychiatry. 1999; 45:817-826. [PubMed: 10202568]

68. Shin LH, McNally RJ, Kosslyn SM, et al. Regional cerebral blood flow during script-driven imagery in childhood sexual abuse-related PTSD: a PET investigation. Am J Psychiatry. 1999; 156:575-584. [PubMed: 10200737] 
69. Shin LM, Kosslyn SM, McNally RJ, et al. Visual imagery and perception in posttraumatic stress disorder: a positron emission tomographic investigation. Arch Gen Psychiatry. 1997; 54:233-237. [PubMed: 9075464]

70. Shin LM, Orr SP, Carson MA, et al. Regional cerebral blood flow in the amygdala and medial prefrontal cortex during traumatic imagery in male and female Vietnam veterans with PTSD. Arch Gen Psychiatry. 2004; 61(2):168-176. [PubMed: 14757593]

71. Semple WE, Goyer P, McCormick R, et al. Higher brain blood flow at amygdala and lower frontal cortex blood flow in PTSD patients with comorbid cocaine and alcohol abuse compared to controls. Psychiatry. 2000; 63:65-74. [PubMed: 10855761]

72. Shin LM, Wright CI, Cannistraro PA, et al. A functional magnetic resonance imaging study of amygdala and medial prefrontal cortex responses to overtly presented fearful faces in posttraumatic stress disorder. Arch Gen Psychiatry. 2005; 62(3):273-281. [PubMed: 15753240]

73. Shin LM, Whalen PJ, Pitman RK, et al. An fMRI study of anterior cingulate function in posttraumatic stress disorder. Biol Psychiatry. 2001; 50:932-942. [PubMed: 11750889]

74. Lindauer RJ, Booij J, Habraken JB, et al. Cerebral blood flow changes during script-driven imagery in police officers with posttraumatic stress disorder. Biol Psychiatry. 2004; 56(11):853861. [PubMed: 15576062]

75. Phan KL, Britton JC, Taylor SF, Fig LM, Liberzon I. Corticolimbic blood flow during nontraumatic emotional processing in posttraumatic stress disorder. Arch Gen Psychiatry. 2006; 63(2):184-192. [PubMed: 16461862]

76. Rauch SL, van der Kolk BA, Fisler RE, et al. A symptom provocation study of posttraumatic stress disorder using positron emission tomography and script driven imagery. Arch Gen Psychiatry. 1996; 53:380-387. [PubMed: 8624181]

77. Sakamoto H, Fukuda R, Okuaki T. Parahippocampal activation evoked by masked traumatic images in posttraumatic stress disorder: a functional MRI study. Neuroimage. 2005; 26(3):813821. [PubMed: 15955491]

78. Bryant RA, Felmingham KL, Kemp AH, et al. Neural networks of information processing in posttraumatic stress disorder: a functional magnetic resonance imaging study. Biol Psychiatry. 2005; 58(2):111-118. [PubMed: 16038681]

79. Protopopescu X, Pan H, Tuescher O, et al. Differential time courses and specificity of amygdala activity in posttraumatic stress disorder subjects and normal control subjects. Biol Psychiatry. 2005; 57(5):464-473. [PubMed: 15737660]

80. Rauch SL, Whalen PJ, Shin LM, et al. Exaggerated amygdala response to masked facial stimuli in posttraumatic stress disorder: a functional MRI study. Biol Psychiatry. 2000; 47(9):769-776. [PubMed: 10812035]

81. Armony JL, Corbo V, Clement MH, Brunet A. Amygdala response in patients with acute PTSD to masked and unmasked emotional facial expressions. Am J Psychiatry. 2005; 162(10):1961-1963. [PubMed: 16199845]

82. Pissiota A, Frans O, Fernandez M, et al. Neurofunctional correlates of posttraumatic stress disorder: a PET symptom provocation study. Eur Arch Psych Clin Neurosci. 2002; 252:68-75.

83. Clark CR, McFarlane AC, Morris P, et al. Cerebral function in posttraumatic stress disorder during verbal working memory updating: a positron emission tomography study. Biol Psychiatry. 2003; 53:474-481. [PubMed: 12644352]

84. Bremner JD, Soufer R, McCarthy G, et al. Gender differences in cognitive and neural correlates of remembrance of emotional words. Psychopharmacol Bull. 2001; 35:55-87. [PubMed: 12397879]

85. Bremner JD, Vythilingam M, Vermetten E, et al. Neural correlates of declarative memory for emotionally valenced words in women with posttraumatic stress disorder (PTSD) related to early childhood sexual abuse. Biol Psychiatry. 2003; 53:289-299.

86. Bremner JD, Vermetten E, Vythilingam M, et al. Neural correlates of the classical color and emotional Stroop in women with abuse-related posttraumatic stress disorder. Biol Psych. 2004; 55(6):612-620.

87. Bremner JD, Vythilingam M, Vermetten E, et al. MRI and PET study of deficits in hippocampal structure and function in women with childhood sexual abuse and posttraumatic stress disorder (PTSD). Am J Psychiatry. 2003; 160:924-932. [PubMed: 12727697] 
88. Shin LM, Shin PS, Heckers S, et al. Hippocampal function in posttraumatic stress disorder. Hippocampus. 2004; 14(3):292-300. [PubMed: 15132428]

89. Bremner JD, Vermetten E, Schmahl C, et al. Positron emission tomographic imaging of neural correlates of a fear acquisition and extinction paradigm in women with childhood sexual abuserelated posttraumatic stress disorder. Psychol Med. 2005; 35(6):791-806. [PubMed: 15997600]

90. Schmahl CG, Elzinga BM, Vermetten E, et al. Neural correlates of memories of abandonment in women with and without borderline personality disorder. Biol Psychiatry. 2003; 54:42-51.

91. Schmahl CG, Elzinga BM, Bremner JD. Individual differences in psychophysiological reactivity in adults with childhood abuse. Clin Psychol Psychother. 2002; 9:271-276.

92. Bremner JD, Randall PR, Vermetten E, et al. MRI-based measurement of hippocampal volume in posttraumatic stress disorder related to childhood physical and sexual abuse: a preliminary report. Biol Psychiatry. 1997; 41:23-32. [PubMed: 8988792]

93. Vermetten E, Schmahl C, Lindner S, Loewenstein RJ, Bremner JD. Hippocampal and amygdalar volumes in dissociative identity disorder. Am J Psychiatry. 2006; 163:1-8. [PubMed: 16390877]

94. Schmahl CG, Vermetten E, Elzinga BM, Bremner JD. Magnetic resonance imaging of hippocampal and amygdala volume in women with childhood abuse and borderline personality disorder. Psych Res Neuroimag. 2003; 122:193-198.

95. Vythilingam M, Heim C, Newport CD, et al. Childhood trauma associated with smaller hippocampal volume in women with major depression. Am J Psychiatry. 2002; 159:2072-2080. [PubMed: 12450959]

96. Bremner JD, Vermetten E. Neuroanatomical changes associated with pharmacotherapy in posttraumatic stress disorder (PTSD). Ann NY Acad Sei. 2004; 1032:154-157.

97. Bremner JD, Mletzko T, Welter S, et al. Treatment of posttraumatic stress disorder with phenytoin: an open label pilot study. J Clin Psychiatry. 2004; 65(11):1559-1564. [PubMed: 15554773]

98. Bremner JD, Mletzko T, Welter S, et al. Effects of phenytoin on memory, cognition and brain structure in posttraumatic stress disorder: a pilot study. J Psychopharmacol. 2005; 19(2):159-165. [PubMed: 15728437]

99. Vermetten E, Vythilingam M, Southwick SM, Charney DS, Bremner JD. Long-term treatment with paroxetine increases verbal declarative memory and hippocampal volume in posttraumatic stress disorder. Biol Psychiatry. 2003; 54(7):693-702. [PubMed: 14512209]

100. Vermetten E, Vythilingam M, Schmahl C, et al. Alterations in stress reactivity after long-term treatment with paroxetine in women with posttraumatic stress disorder. Ann NY Acad Sei. 2006; 1071:184-202.

101. Fernandez M, Pissiota A, Frans O, et al. Brain function in a patient with torture related posttraumatic stress disorder before and after fluoxetine treatment: a positron emission tomography provocation study. Neuwsci Lett. 2001; 297:101-104.

102. Seedat S, Warwick J, van Heerden B, et al. Single photon emission computed tomography in posttraumatic stress disorder before and after treatment with a selective serotonin reuptake inhibitor. J Affect Disord. 2003; 80:45-53. [PubMed: 15094257]

103. Astur RS, St Germain SA, Tolin D, Ford J, Russell D, Stevens M. Hippocampus function predicts severity of posttraumatic stress disorder. Cyberpsychol Behav. 2006; 9(2):234-240. [PubMed: 16640486]

104. Semple WE, Goyer PF, McCormick R, et al. Attention and regional cerebral blood flow in posttraumatic stress disorder patients with substance abuse histories. Psychiatry Res Neuroimaging. 1996; 67:17-28. [PubMed: 8797239]

105. Zubieta J-K, Chinitz JA, Lombardi U, Fig LM, Cameron OG, Liberzon I. Medial frontal cortex involvement in PTSD symptoms: A SPECT study. J Psychiatry Res. 1999; 33:259-264. 


\section{Key issues}

- Functional imaging with functional magnetic resonance imaging, positron emission tomography and single photon-emission computed tomography can be used to identify brain circuits that underlie symptoms of posttraumatic stress disorder (PTSD).

- TSD is associated with increased amygdala function and decreased function in the medial prefrontal cortex and hippocampus.

- Atidepressants promote neurogenesis in the hippocampus and increase hippocampal volume in PTSD patients.

- Future studies are needed to assess the effects of antidepressants on brain function in PTSD. 


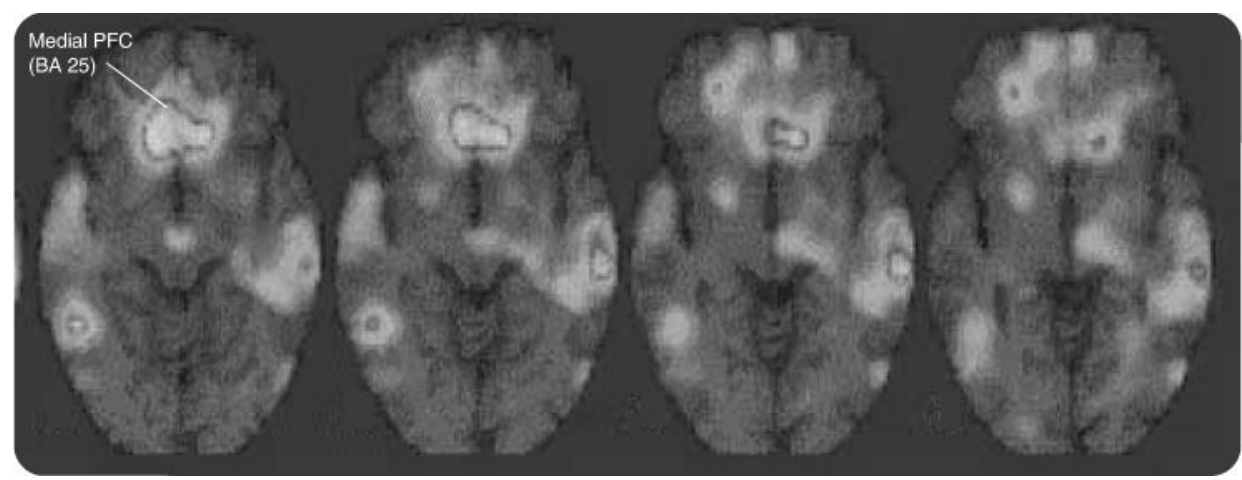

Figure 1. Decreased medial prefrontal function with exposure to combat related slides and sounds

There was a decrease in function in the MPFC in combat veterans with PTSD relative to combat veterans without PTSD with exposure to traumatic combat material. Reprinted from [63] with permission from the Society of Biological Psychiatry.

BA: Brodmann's Area; mPFC: Medial prefrontal cortex; PTSD: Posttraumatic stress disorder. 

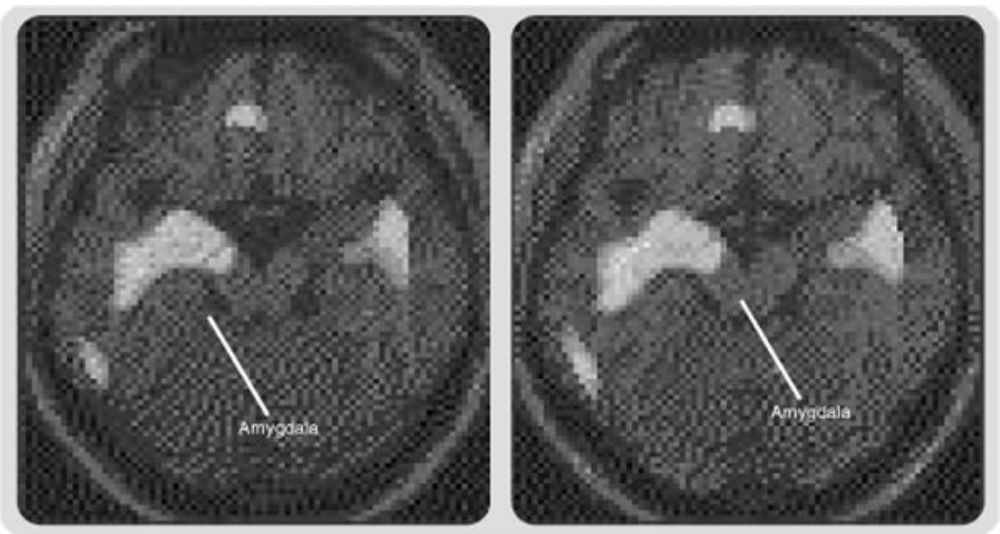

Figure 2. Increased amygdala function during acquisition of conditioned fear responses in women with early childhood abuse and posttraumatic stress disorder

Yellow areas represent bilateral amygdala activation. There was greater amygdala activation with acquisition of fear responses (pairing of conditioned stimulus and unconditioned stimulus) in posttraumatic stress disorder compared with controls. Reprinted with permission from [89]. 


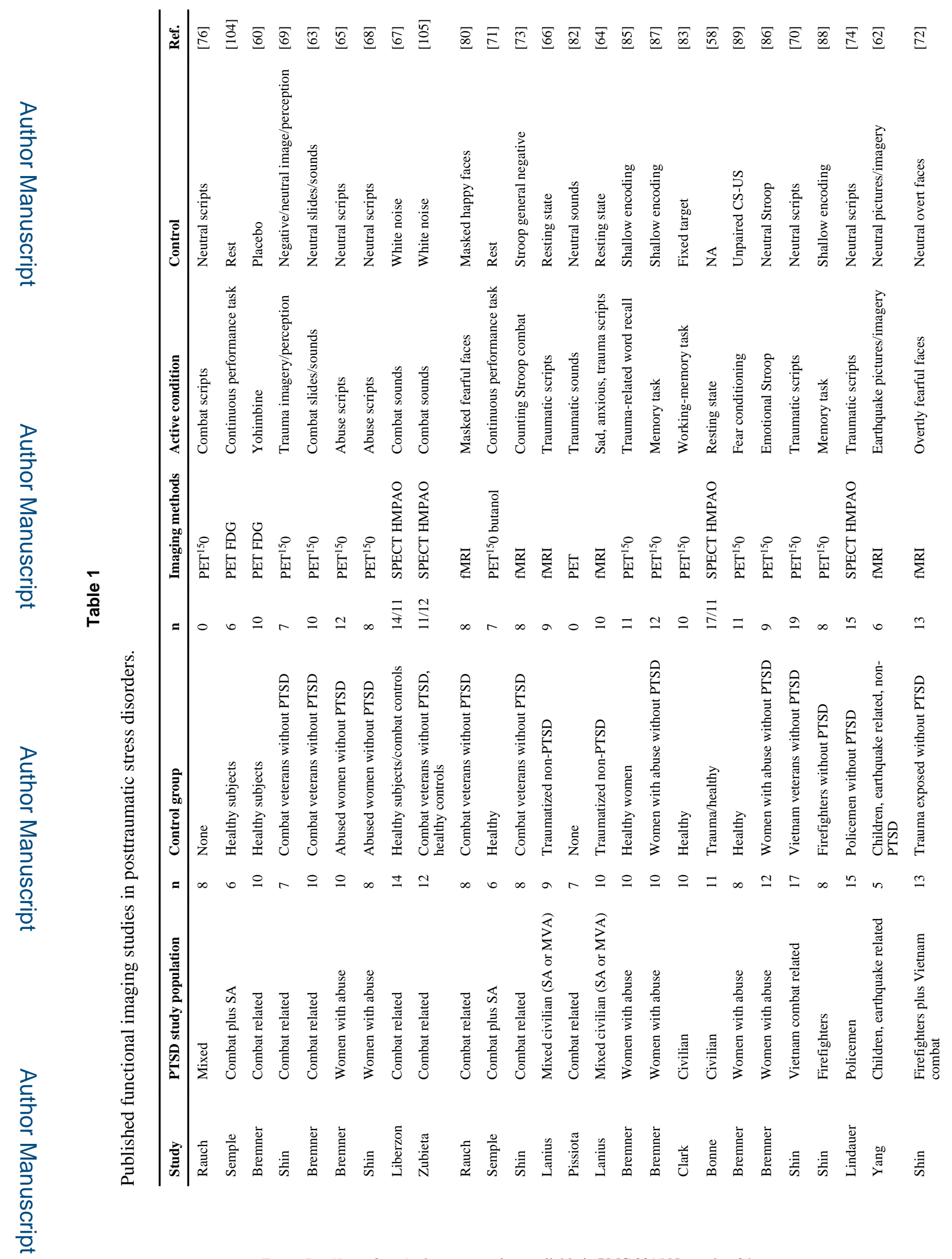

Expert Rev Neurother. Author manuscript; available in PMC 2015 November 24. 


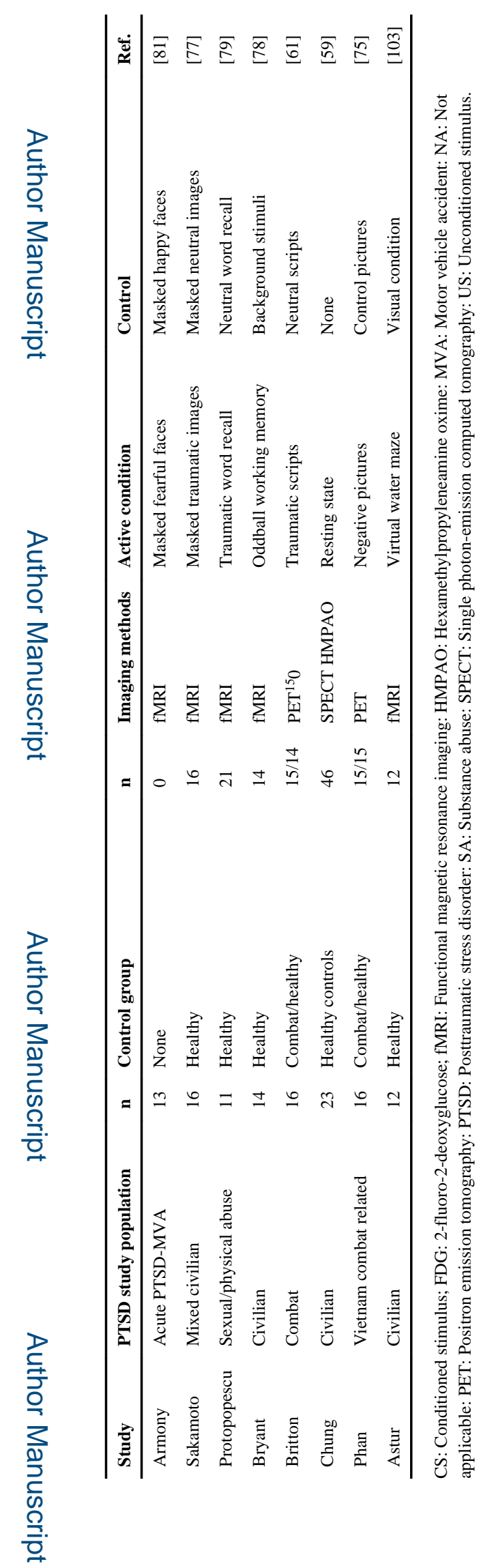

Expert Rev Neurother. Author manuscript; available in PMC 2015 November 24. 


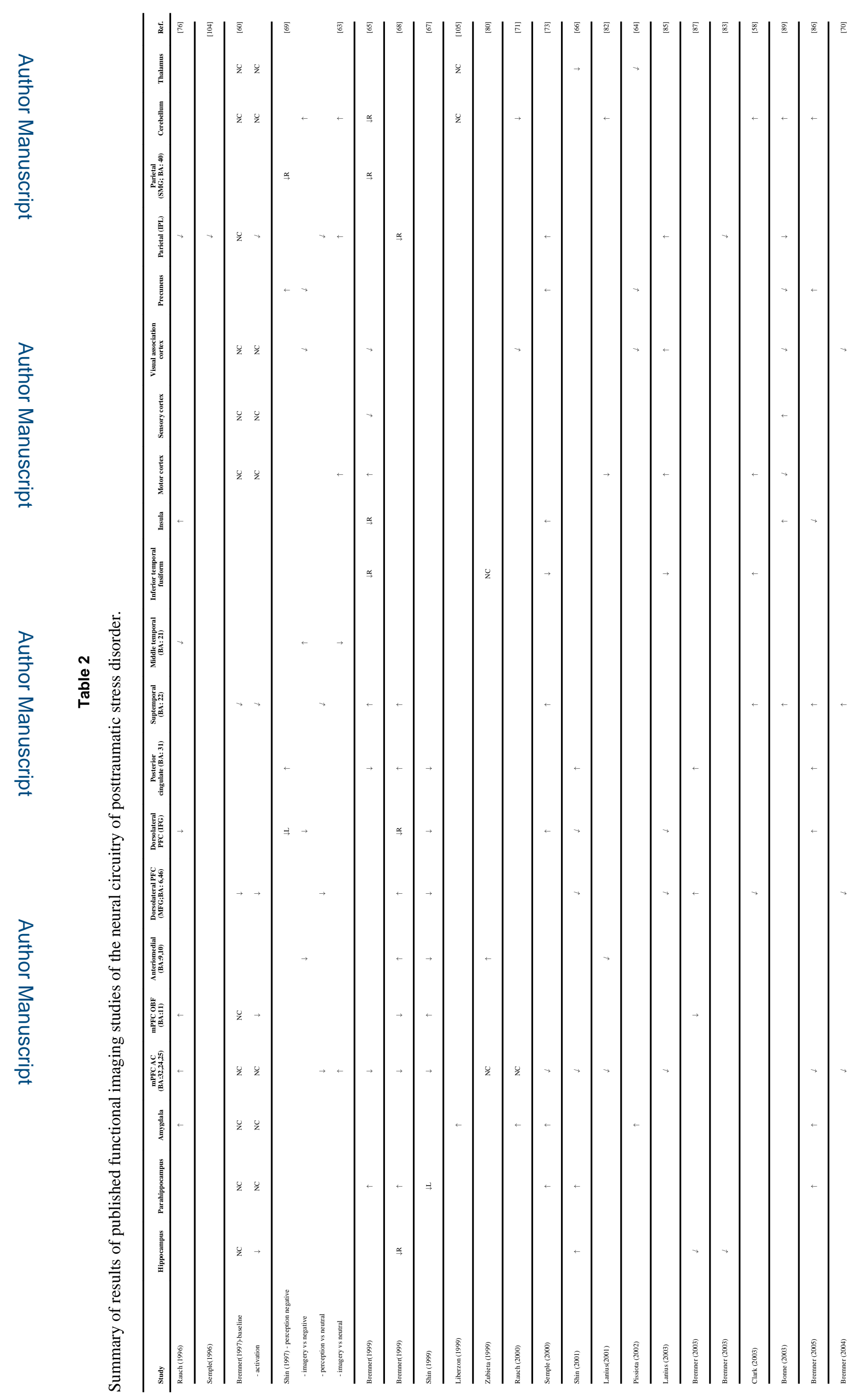




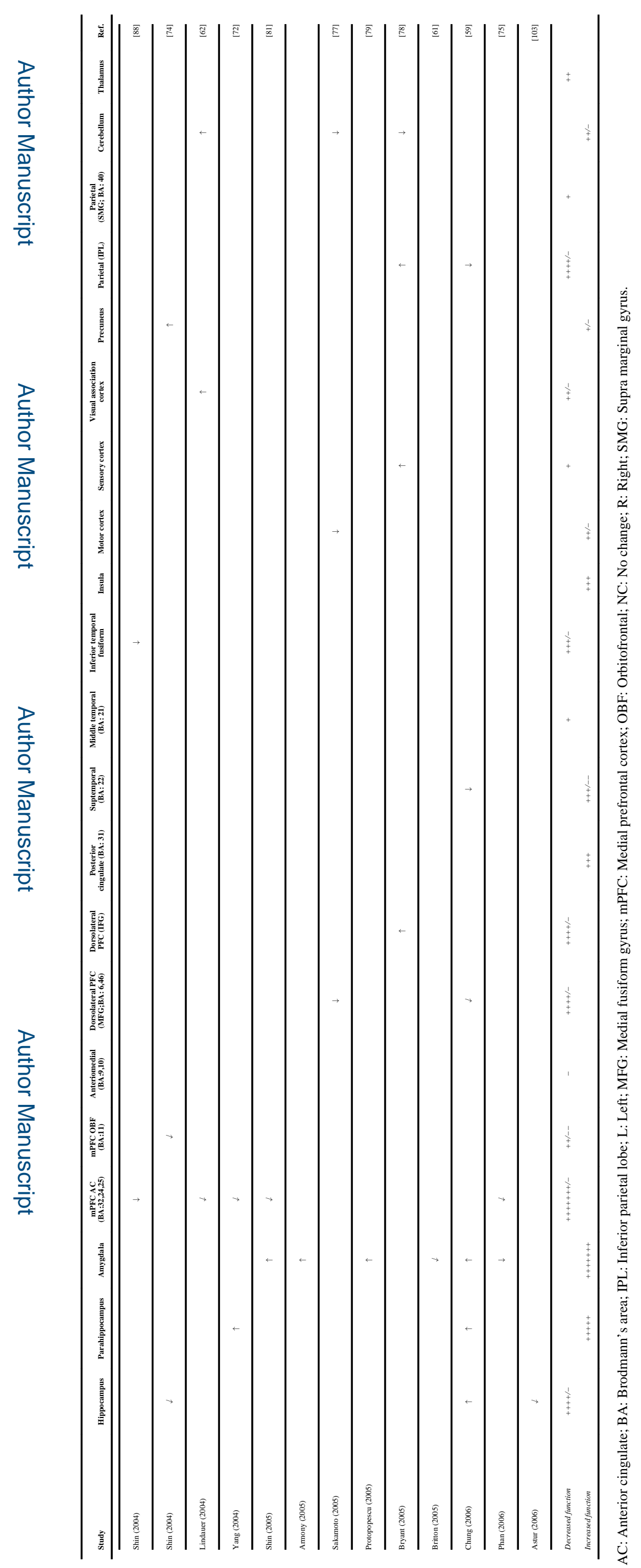

